\title{
Fish Ladder Geometrical Sizes and Hydraulic Performances. Experimental Approach
}

\author{
Cristina-Catalina Petica $^{1}$, Carmen-Anca Safta $^{1, *}$, Irina Pincovschi ${ }^{1}$ and Lucian Mandrea ${ }^{1}$ \\ ${ }^{1}$ University Politehnica of Bucharest, Faculty of Power Eng., 313 Splaiul Independentei, 060042, \\ Bucharest, Romania
}

\begin{abstract}
The paper presents the hydraulic experimental results from different types of fish ladders heaving pools and baffles with submerged orifice or vertical slot. The goal of the experiments is to develop a database of velocities and power densities for each type of fish ladder with the baffles in different arrangements, for different lengths of the pools. So, based on the fish ladder type, the hydraulic characteristic database and the experimental laboratory model size provided by this study, one can improve the design of a fish ladder. The laboratory experimental model is designed with respect to Froude similarity criterion.
\end{abstract}

\section{Introduction}

Fish ladders must facilitate the passing of aquatic biota along the river from downstream to the upstream, or vice versa, when river cross-section is blocked by hydraulic structures. The transverse obstacles could be weirs, intake weirs, check dams, barrages, or small hydropower plants (SHP). According to the Romanian Water Law (107/1996) the newly built obstacles that require fish passes are the ones with heights higher than $0.5 \mathrm{~m}$, up to $13.6 \mathrm{~m}$.

Fish ladders (or fish passages, or fish ways) are hydraulic structures of slope channel type usually having the length divided by baffles into pools. Through the baffles the water flows over weirs, through slots or submerged orifices.

The Romanian Water Law (107/1996) [1] stipulates in the article 53, item 4 that the new barrage or water intake located across the watercourses must be provided with facilities to insure the longitudinal continuity and a servitude flow rate (which is the sum of the ecological flow and the discharge necessary to supply the downstream users, as it is defined in section 26 of annex no. 1). As appropriate, the facility should include construction works to ensure the migration of aquatic fauna, especially of the ichthyofauna, in order to achieve the environmental objectives (stipulated in art. $2^{1}$, in compliance with the provisions of art. $2^{4}$ ). In the same law it is also highlighted that the applied technical solutions must be feasible and without "disproportionate costs".

The Romanian energy and rural development policies from the last decade encouraged the development of renewable energies. Small hydropower plants usually built on small

* Corresponding author: $\underline{\text { safta.carmenanca@gmail.com }}$ 
rivers within rural areas represent an important renewable energy source. More than 450 SHPs have been inventoried in Romania by 2016 [2].

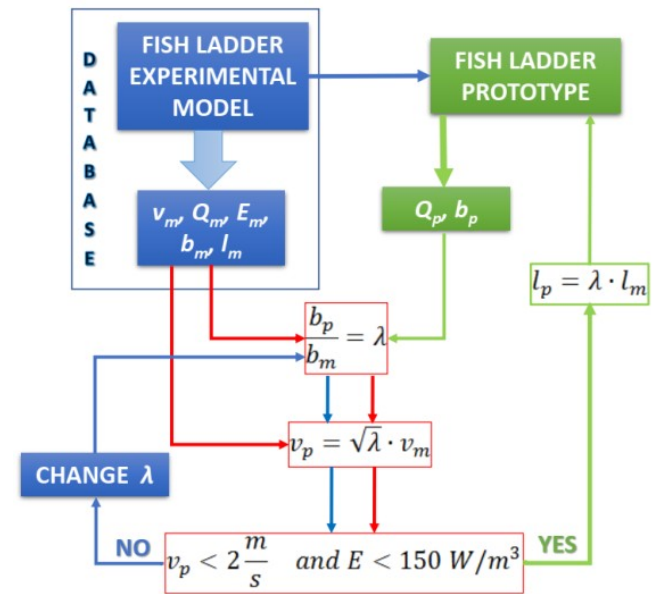

Fig. 1. Flowchart of the fish ladder design process developed based on experimental hydraulic characteristics included in the experimental database; where $v, Q, E, l$ and $b$ are symbols for velocity, flow rate, power density, length and width, respectively; $\lambda$ is the scale factor and the subscripts $p$ and $m$ indicate the prototype and the model.

The presence of river cross-section hydraulic structures without fish passages may have a strong negative impact on the longitudinal migration of aquatic biota. To protect the environment and to connect the upstream and downstream reaches along the stream a fish ladder must be properly designed and built.

In the study published by Luca E. [3] it is specified that " $15 \%$ from the fish ladders in Romania are inefficient". The non-efficiency of the ladders means their hydraulic parameters and water biological conditions (temperature, biological dissolved oxygen, light intensity etc.) do not comply with fish migration conditions and therefore fish will not pass it. This is due to a poor design that does not provide these optimal conditions suitable with the behaviour of fish species. Fish ladder performances depend mainly on water velocity, depth, degree of turbulence, hydraulic losses, the geometrical sizes of the pools, channel bottom roughness, flow direction [4].

The objective of this paper is to analyse experimentally the hydraulic behaviour of different types of fish ladders with pools and baffles having submerged orifice or vertical slot and to gather all results in a data base which could be used in the fish ladders design.

In Figure 1 is presented the flowchart of the design process on a knowledge data base of fish ladders hydraulic behaviour.

The hydraulic parameters of velocity and power density of different types of fish ladders were compared with those measured for different arrangements of the baffles (in line or zigzag ) and different length of the pools.

For the experiments a flume was designed for geometrical sizes and flow rate which are specific to small hydropower plants $(\mathrm{SMH})$ having fish ladders with flow rates, usually between $40 \mathrm{l} / \mathrm{s}$ to $400 \mathrm{l} / \mathrm{s}$.

\section{Fish ladder hydraulic characteristics}

The review of scientific papers and technical reports regarding fish ladder design $[4 \div 9]$ mentions that the design of fish ladders has a systemic approach and the overall compliance of the biological, hydraulic, thermic, hydrological and economic conditions must be considered. 
There are different types of fish ladders according to different classification criteria, mainly: pools and weirs (including the submerged orifices), vertical slots, Denil, close-tonature and culvert $[6 \div 8]$. These types of fish ladders are widespread in association with the small hydropower plants (mainly run of river - RoR). Other types of fishways are fish locks and lifts, which are usually used on larger rivers and/or with high dams [7].

The DVWK technical report [6] states that depending of the fish species and size, the hydraulic requirements for baffle fish ladders are: flow velocities in the orifices (of fish ladders with submerge orifices) or in the vertical slots ( $v_{s}$ in Figure 1) should not exceed $2.0 \mathrm{~m} / \mathrm{s}$. Also, the flow power density, $E$, in terms of its volumetric dissipation, should not exceed $150 \mathrm{~W} / \mathrm{m}^{3}$ for most fish species, even $200 \mathrm{~W} / \mathrm{m}^{3}$ for salmonids, so that the lowturbulence flow regime in the pool should be ensured [6].

With the notations from Figure 2, the flow velocity through the submerged orifice and the power density are calculated with $[6,8]$ :

$$
\begin{aligned}
& v_{s}=\sqrt{2 g \Delta h}, \\
& E=\frac{\rho g \Delta h Q}{b h_{m}\left(l_{b}-d\right)}
\end{aligned}
$$

where $Q$ is the flow rate with $Q=Q_{s}+Q_{a}$, where $Q_{\mathrm{s}}$ and $Q_{\mathrm{a}}$ are the flow rates through the submerge orifice and the slot, respectively.

In relation (1) $v_{s}$ is the theoretic velocity. The real velocity through on a submerged orifice depends on the coefficient of velocity, $=\sqrt{\frac{1}{1+\varsigma}}$, caused by friction loss (with $\varsigma$ loss coefficient [9]). If the flow is in the turbulent rough regime (with Reynolds number $\operatorname{Re}>200,000) \varphi=1$ [9, pp. 230] and $v_{s}$ is calculated with equation (1), else the velocity is calculated with formulae $v_{s}=\varphi \sqrt{2 g \Delta h}$, and $\varphi=\varphi(\mathbf{R e})$.

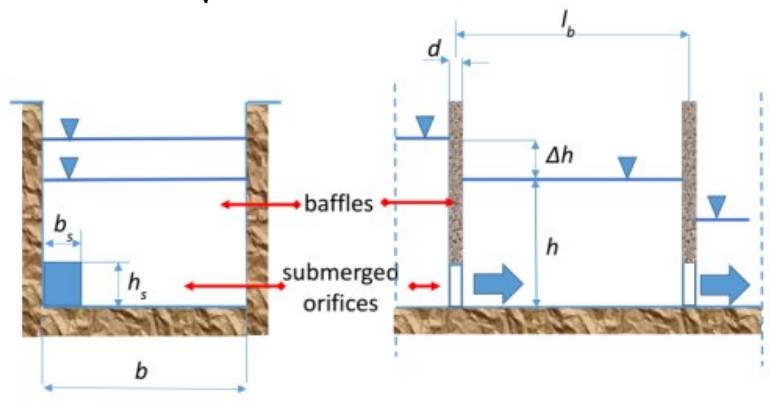

a)

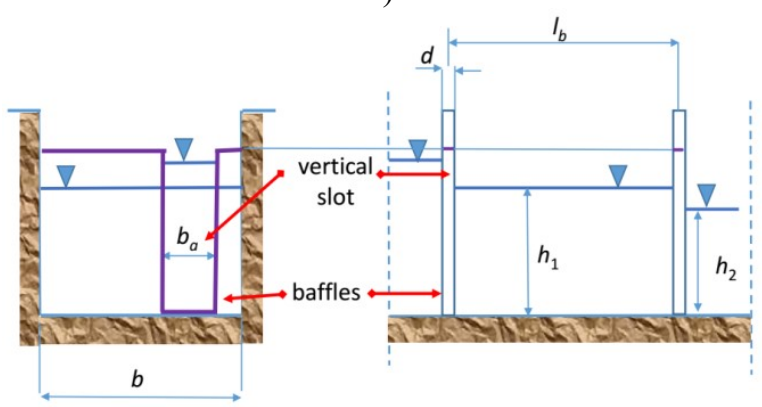

b)

Fig. 2. Longitudinal and cross-section profiles through fish ladders with submerged orifices (a) and slots (b). 
The discharge in the orifice is $Q_{s}=\psi \cdot b_{s} \cdot h_{s} \sqrt{2 g \Delta h}$ with the discharge coefficient $\psi=0.65$ to 0.85 [6]. The flow rate through the slot is:

$$
Q_{a}=\frac{2}{3} C_{s} b_{a} \sqrt{2 g}\left(h_{1}\right)^{3 / 2},
$$

where $h_{1}$ is the mean level of the flow in the pool upstream of the baffle; and $C_{s}$ is the discharge coefficient for slots given by Villmonte as:

$$
C_{s}=\beta_{0}\left[1-\left(\frac{h_{2}}{h_{1}}\right)^{1.5}\right]^{0.385} .
$$

The coefficient $\beta_{0}$ depends on the geometry of the slot, pool dimensions, and the discharge equation used [8]. It was considered that $\beta_{0}=0.705$ for a flow rate $0.455 \mathrm{~m}^{3} / \mathrm{s}$ as it was measured $[8,10]$. In equation $4, h_{2}$ is the mean level of the flow in the pool downstream of the baffle, Fig. 2.b.

In the literature, the geometrical sizes of the pool and the slot width must be proportional with the fish size. Also, according to USFWS technical report, the pool length should be ten times the orifice width and the pool width should be eight times the orifice width ( $b_{s}$ or $b_{a}$, Fig. 2) [11].

The above indications were considered in the dimensioning of baffles (with submerged orifice or slot) and pools fish ladder experimental model built in the laboratory.

\section{Experimental setup}

The measurements of the hydraulic characteristics of different types of fish ladder, were carried out on the experimental setup in Figure 3.

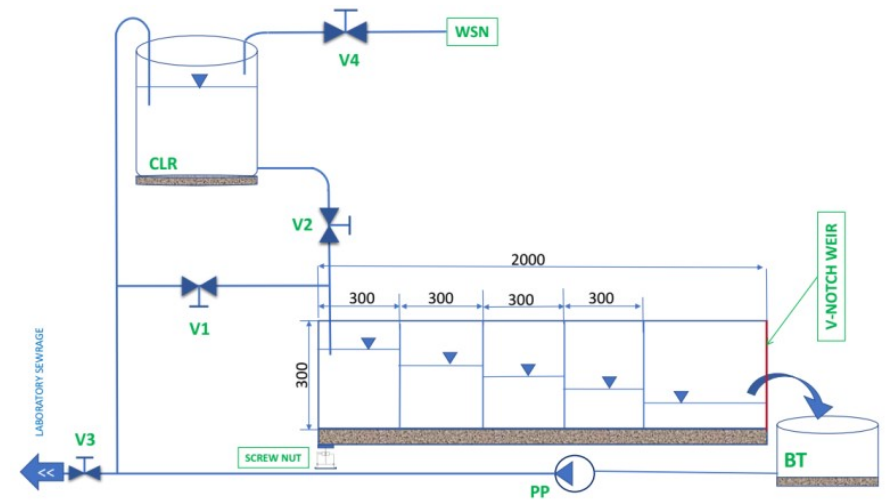

Fig. 3. Sketch of the experimental setup.

The testing facility has a hydraulic flume which is $2 \mathrm{~m}$ long, $0.24 \mathrm{~m}$ wide and $0.3 \mathrm{~m}$ high; a constant level reservoir (CLR, $0.1 \mathrm{~m}^{3}$ capacity); a buffer tank (BT, $0.1 \mathrm{~m}^{3}$ capacity); a radial pump (PP, Grundfos type UPS 15-50 CES 87); four valves (V1-V4, 1 inch diameter), and flexible pipes ( 1 inch diameter, except for the supply pipe of the pump which is $1-1 / 2$ inch diameter) [12].

The flume was designed to comply with the Froude hydrodynamic similarity criterion $\left(F r=V^{2} /(g \cdot L)\right)$ so that the prototype discharge should range between $0.04-0.4 \mathrm{~m}^{3} / \mathrm{s}$, which is usually common for the fish ladders of SHP RoR. The scale factor $\lambda=L_{p} / L_{m}$ was chosen $\lambda=25 / 1$, to avoid scale effects caused by the viscous forces, as Chanson recommend [13]. In the definition of scale factor $\lambda$, the subscripts $p$ and $m$ are for prototype and model. 
The flume is divided into pools with adjustable length, by using removable baffles (Figure 4, Figure 5) with different geometrical configurations, specific for fish ladders with pools and weirs. The baffles can have a submerged orifice or a slot, placed laterally or central, across the section (Figure 6). More details regarding the manufacture of the flume are in reference [12].

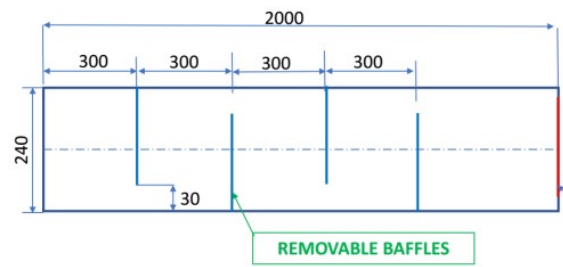

a)

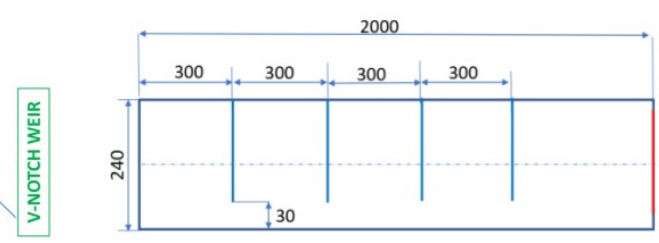

b)

Fig. 4. The fish ladder with the removable baffles in different arrangements: (a) zigzag; (b) in line.
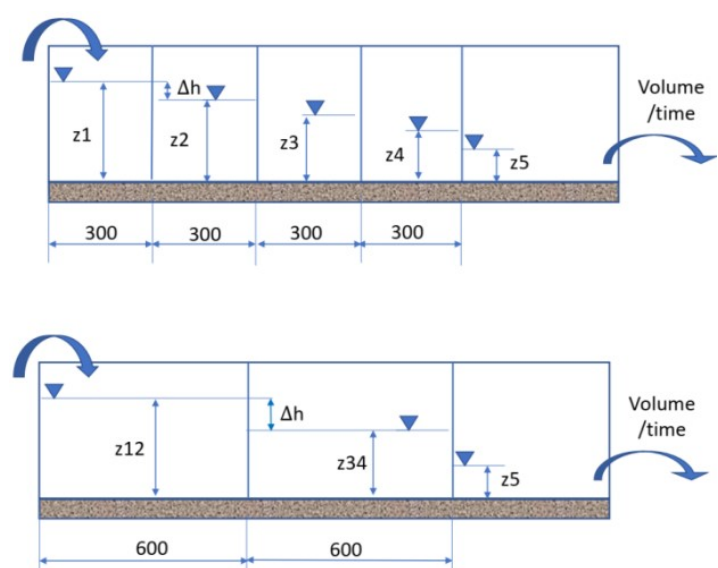

Fig. 5. Sketches of the fish ladder with baffle arrangement for different pool lengths

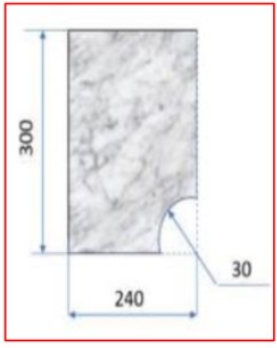

a)

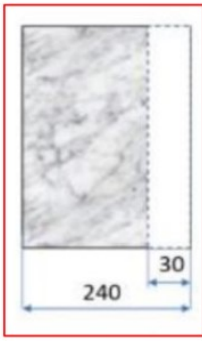

b)

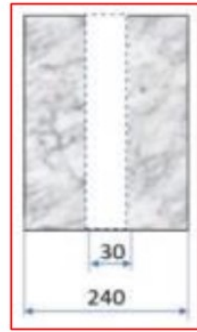

c)

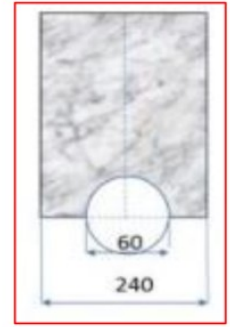

d)

Fig. 6. Different types of baffles: (a) with lateral submerged orifice, LSO; (b) with lateral vertical slot, LVS; (c) with vertical slot placed in the middle of the baffle, MVS; (d) with submerged orifice placed in the middle of the baffle, MSO.

At the downstream end of the flume there is a $90^{\circ} \mathrm{V}$-notch (with a $100 \mathrm{~mm}$ wall height). The weir was calibrated by measuring the discharge volumetrically (volumetric flow rate $Q=V / t)$ and the water level $(h)$ above the crest, leading to the rating curve with the equation $Q=0.5353 h^{2.3788}$.

The flume can operate with slopes from zero to $5 \%$ by adjusting a screw nut at the upstream end of the channel (as in Figure 3). The experiments were carried out on the flume with zero slope because only a structure without slope can provide the non- 
uniformity flow conditions between pools $[8,10,14,15]$. A fish needs to swim faster than the velocities in the slots when moving upstream and for this reason the uniform flow conditions in the design of fish ladders are not recommended [14, 15].

In this experimental study the roughness of the flume was not considered because only by using a distorted model the bed geometry and the roughness could be included [13].

The ratios between corresponding hydrodynamical parameters in prototype and model namely length $(L)$, time $(t)$, velocity $(V)$, flow rate $(Q)$, force $(F)$, pressure $(p)$ and power density $(E)$ with respect to Froude similarity are shown in Table 1, considering the same fluid ( $\rho_{p}=\rho_{m}$, where $\rho$ is the fluid density).

Table 1. Rations between corresponding parameters in prototype and model.

\begin{tabular}{|c|c|c|c|c|c|c|c|}
\hline Ratio & $L_{p} / L_{m}$ & $t_{p} / t_{m}$ & $V_{p} / V_{m}$ & $Q_{p} / Q_{m}$ & $F_{p} / F_{m}$ & $p_{p} / p_{m}$ & $E_{p} / E_{m}$ \\
\hline $\begin{array}{c}\text { Froude } \\
F r=V^{2} /(g \cdot L)\end{array}$ & $\lambda$ & $\lambda^{1 / 2}$ & $\lambda^{1 / 2}$ & $\lambda^{5 / 2}$ & $\lambda^{3}$ & $\lambda$ & $\lambda^{1 / 2}$ \\
\hline
\end{tabular}

The fish ladders prototypes are considered to have the flow rates in the range of $(0.04 \div 0.4) \mathrm{m}^{3} / \mathrm{s}$, which is specific for the RoR SHPs.

\section{Results and discussions}

Using the experimental set up presented above, the hydraulic parameters of velocity and power density $(v, E)$ for different types of fish ladder, having a simplified vertical slot baffle (Fig. 6), were measured and calculated.

Twelve different scenarios were considered (in Table 2) by changing the baffle type and the pool length in the flume. A short pool is $300 \mathrm{~mm}$ long, and a long pool is $600 \mathrm{~mm}$, as in Figure 5. Each baffle (Fig. 6) was placed in multiple possible arrangements (Fig. 4):

- $\quad$ zigzag in short pools, for LVS and LSO baffles (Fig. 6.a and Fig. 6.b);

- $\quad$ in-line in short pools, for LVS and LSO baffles;

- $\quad$ zigzag in long pools, for LVS and LSO baffles;

- in-line in long pools, for LVS and LSO baffles;

- central openings in short pools, for MVS and MSO baffles (Fig. 6.c and Fig. 6.d);

- central openings in long pools, for MVS and MSO baffles.

Table 2. Scenarios considered in relation with baffles type from figure 6

\begin{tabular}{|c|c|c|c|c|}
\hline Pool length & \multicolumn{2}{|c|}{ Short pools } & \multicolumn{2}{|c|}{ Long pools } \\
\hline arrangements & Zigzag & In-line & Zigzag & In-line \\
\hline \multicolumn{5}{|l|}{ Baffles Type } \\
\hline LVS (lateral vertical slot) & Scenario 1 & Scenario 2 & Scenario 3 & Scenario 4 \\
\hline LSO (lateral submerged orifice) & Scenario 5 & Scenario 6 & Scenario 7 & Scenario 8 \\
\hline MVS (middle vertical slot) & \multicolumn{2}{|c|}{ Scenario 9} & \multicolumn{2}{|c|}{ Scenario 10} \\
\hline MSO (middle submerged orifice) & \multicolumn{2}{|c|}{ Scenario 11} & \multicolumn{2}{|c|}{ Scenario 12} \\
\hline
\end{tabular}


The flow rate can be adjusted by using a variable flow centrifugal pump in close circuit and by operating with the constant level reservoir (CLR) in an open circuit [12]. For each flow rate the levels in the centre of pools were measured.

The hydraulic characteristics (velocity in the orifice/slot and the power density) were calculated for each level measured between the pools. The results obtained on the model were transposed on the prototype by using the relations in Table 1.

The results obtained on the prototype are plotted in Figures 7 and 8.

In all scenarios the values of power density are much less than the maximum limit given in the literature, of $150 \mathrm{~W} / \mathrm{m}^{3}$ [6]. However, in terms of velocity, one can notice that the limit of $2 \mathrm{~m} / \mathrm{s}$ is exceeded in the case of baffle with the submerged orifice in the shape of a quarter of circle, placed in the corner of the baffle (Scenarios 5, 67 and 8). This observation is valid for short and long pools, as well as in-line and zigzag arrangements (Figure 7.a and Figure 8.a).

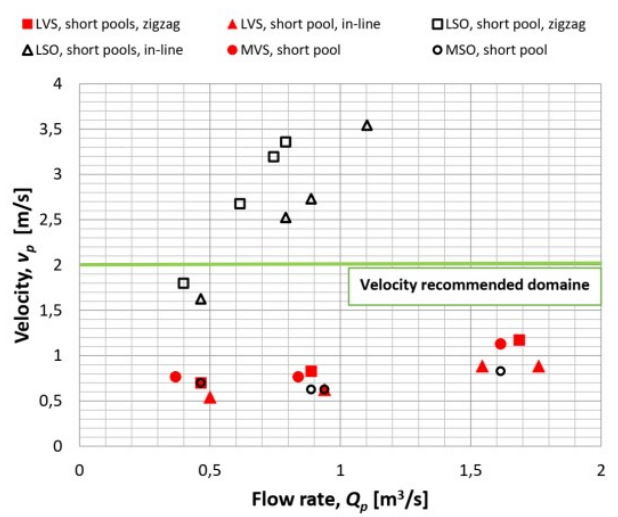

a)

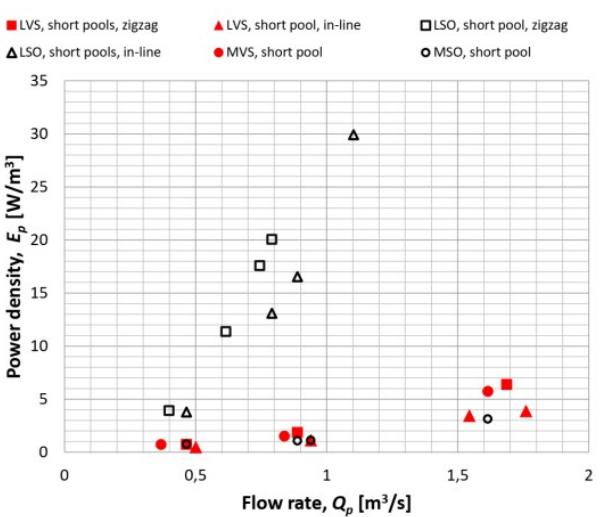

b)

Fig. 7. Short pools scenarios: (a) velocities vs. flow rates; (b) power density vs. flow rates.

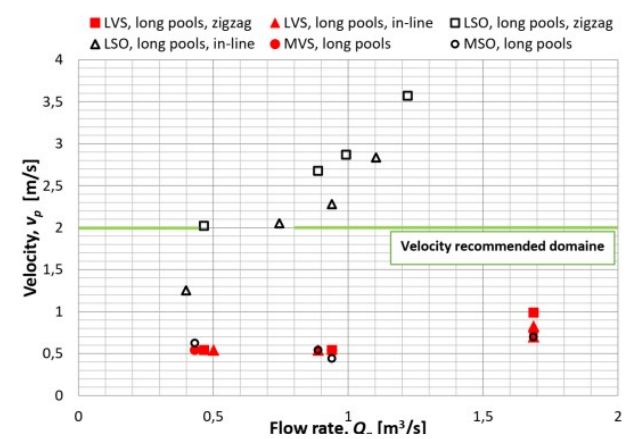

a)

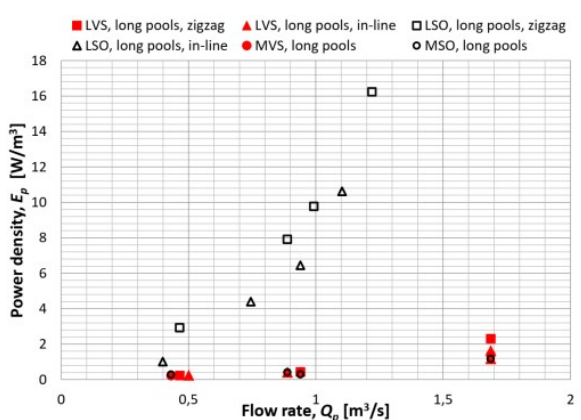

b)

Fig. 8. Long pools scenarios: (a) velocities vs. flow rates; (b) power density vs. flow rates.

The hydraulic behaviour of the vertical slot baffles is comparable with baffles having the submerged orifice in the middle of the baffle, MSO. The velocities are in the range of 0.5 to $1.2 \mathrm{~m} / \mathrm{s}$ and power density is less than $10 \mathrm{~W} / \mathrm{m}^{3}$ in the case of short pools, Fig. 7 .

In the case of long pools, the velocities are not very well individualized for each scenario even if the range of velocity remains approximately the same $(0.5$ to $1.0 \mathrm{~m} / \mathrm{s})$. Because the volume of water increases in the pool, the power density is lower in long pool scenarios than in short pool scenarios. 
The velocities obtained on the fish ladder with vertical slot and the slot placed in the middle (MVS case - Scenario 9) are comparable with the velocities through the lateral vertical slot arranged in zigzag (LVS case - Scenario 1) but less than in the case of LVS arranged in-line, Scenario 2. This trend is found in the scenarios with long pools, too.

\section{Conclusions}

The paper presents the experimental results of different types of fish ladders having a vertical slot baffle or a submerged orifice, which were carried out on an experimental laboratory model. The test facility was designed to allow experiments on baffle fish ladders with pools and submerged circular orifices, or pools and vertical slots in different arrangements and different pool lengths.

The measurements were performed in twelve distinguished scenarios for which the velocity through the orifices and the power density in the pools were calculated. The results obtained on the model were transposed on the prototype considering Froude similarity. The scale factor was chosen $25(\lambda=25)$ to avoid scale effects.

The results show that the fish ladder having a vertical slot baffle has a hydraulic behaviour close to the fish ladders with submerged orifices placed in the middle. For this type of vertical slot, the baffles arrangements, in zigzag or in-line, are not very important, the velocities obtained being approximately the same.

For a fish ladder design, it is important that the proportion of geometrical sizes of the pools (length and width), which depend on the dimension of the submerged orifice or the slot width should be kept (length $=10 \times$ orifice or slot width and width $=8 \times$ orifice or slot width). Otherwise the fish ladder could become inefficient and therefore unattractive for the fish.

The goal of the study was to obtain an experimental database of hydraulic characteristics of different types of fish ladders which can be used in fish ladder design. The experimental results obtained on the experimental model should be compared with the ones available in the literature, so a further development of the study is required.

\section{References}

1. Romanian Water Law (107/1996) amended and supplemented with the Government Emergency Ordinance OUG no. 78/2017 published in the Monitorul Oficial no. 885 from the $10^{\text {th }}$ of Nov. 2017, http://www.monitoruloficial.ro)

2. B.Popa, Microhidroenergia astazi, in Romania. Romanian HydroPower energy summit, februarie 2016, http://govnet.ro/uploads/files/11_ARmHE GOVNET.pdf

3. E. Luca, Practici mondiale privind solutii de asigurare a migrarii ihtiofaunei si posibilitatea aplicarii acestora in Romania, Institutul National de Hidrologie si Gospodarirea apelor, Conferinta stiintifica anuala, 1-3 nov. 2011, https://www.scribd.com/doc/222635287/Practici-Mondiale-Privind-AsigurareaMigrarii-Faunei-Piscicole

4. J. O'Connor, M. Mallen-Cooper, I. Stuart, Performance, operation and maintenance guidelines for fishways and fish passage works, Technical Report Series No. 262 for the Water and Catchments Group, Department of Environment, Land, Water and Planning. Arthur Rylah Institute for Environmental Research, Department of Environment, Land, Water and Planning, Heidelberg, Victoria, Arthur Rylah Institute for Environmental Research, (2015), https://www.ari.vic.gov.au/_data/assets/pdf_file/0024/39453/ARI-Technical-Report- 
262-Performance-operation-maintenance-guidelines-for-fishways-and-fish-passageworks.pdf

5. T. Linnansaari, B. Wallace, R.A. Curry, G. Yamazaki, (2015). Fish Passage in Large Rivers: A Literature Review. Mactaquac Aquatic Ecosystem Study Report Series 2015016. Canadian Rivers Institute, University of New Brunswick $\mathrm{v}+55 \mathrm{p}$, https://www.researchgate.net/publication/308558211 FISH_PASSAGE_IN_LARGE RIVERS A L LITERATURE_REVIEW/download (10/04/2019)

6. DVWK, Fish passes - Design, dimensions and monitoring, Published by the Food and Agriculture Organization of the United Nations in arrangement with Deutscher Verband für Wasserwirtschaft und Kulturbau e.V. (DVWK) Rome, (2002), http://www.fao.org/3/y4454e/y4454e00.htm

7. EPRI, Upstream and Downstream Fish Passage and Protection Technologies for Hydroelectric Application: A Fish Passage and Protection Manual, EPRI, Pala alto, CA: (2002). 1005392, http://hydrovolts.com/wp-content/uploads/2012/02/Upstreamand-Downstream-Fish-Passage-Technologies-for-Hydroelectric-Application.pdf

8. J. F. Fuentes-Pérez, A. García-Vega, F. J. Sanz-Ronda, A. Martínez de Azagra Paredes, Villemonte's approach: a_general method for modeling uniform and non-uniform performance in stepped fishways. Knowl. Manag. Aquat. Ecosyst., 418, 23, (2017).

9. D. Cioc, Hidraulica, Ed. Didactica \& Pedagogica, Bucharest, (1983).

10. N. Rajaratnam, C. Katopodis, S. Solanki, New designs for vertical slot fishways. Can J Civil Eng 19: 402-414, (1992).

11. USFWS (U.S. Fish and Wildlife Service), Fish Passage Engineering Design Criteria, (2017), https://www.fws.gov/northeast/fisheries/pdf/USFWS_R5_2017_Fish_Passage_ Engineering_Design_Criteria.pdf

12. C-C. Petica, C-A. Safta, I. Pincovschi, L. Mandrea, Experimental Laboratory Model of a Fish Ladder Used in the Small Hydropower Plants, The 11th International Symposium on ATEE, March 28-30, (2019), Bucharest, Romania, 978-1-7281-01019/19/\$31.00 (2019 IEEE (to be published).

13. H. Chanson, Hydraulics of Open Channel Flows: An Introduction, 512 pp., Chaper 14, Eduard Arnold, London, (1999).

14. J.F. Fuentes-Perez, A.T. Silva, J.A. Tuhtan, A. García-Vega, R. Carbonell-Baeza, M. Musall, M. Kruusmaa, 3D modelling of non-uniform and turbulent flow in vertical slot fishways, Environmental Modelling \& Software 99 (2018), pp. 156-169.

15. Fuentes-Pérez JF, Sanz-Ronda FJ, Martínez de Azagra-Paredes A, García-Vega A, Martínez de Azagra A, García-Vega A. 2016. Nonuniform hydraulic behavior of poolweir fishways: a tool to optimize its design and performance. Ecol Eng 86: 5-12. 